\title{
PERTUMBUHAN DAN HASIL TANAMAN JAGUNG KETAN \\ TANPA OLAH TANAH TUGAL LANGSUNG PASCA PADI KONVENSIONAL DAN SISTEM AEROBIK TUMPANGSARI KACANG TANAH
}

\section{GROWTH AND YIELD OF ZERO-TILLAGE WAXY MAIZE DIRECT-SEEDED FOLLOWING CONVENTIONAL AND AEROBIC RICE INTERCROPPED WITH PEANUT}

\author{
Ni Wayan Dwiani Dulur¹, Wayan Wangiyana, Nihla Farida, dan I Gusti Made Kusnarta \\ Fakultas Pertanian, Universitas Mataram \\ E-mail: dwiani.dulur@unram.ac.id ${ }^{1}$
}

\begin{abstract}
ABSTRAK
Di lahan sawah, petani umumnya menanam tanaman palawija termasuk tanaman jagung pada musim kemarau setelah padi sawah, ketika ketersediaan air irigasi tidak cukup untuk tanam padi. Penelitian ini bertujuan untuk mengetahui pengaruh teknik budidaya padi antara sistem konvensional dan sistem irigasi aerobik pada bedeng tumpangsari dengan kacang tanah terhadap pertumbuhan dan komponen hasil tanaman jagung ketan varietas lokal Bima, yang ditugal langsung pasca padi tanpa olah tanah. Percobaan dilaksanakan di lahan sawah Desa Beleke, Kecamatan Gerung, Lombok Barat, dari bulan September sampai Desember 2018, yang ditata menurut Rancangan Split Plot dengan tiga blok (ulangan) dan dua faktor perlakuan. Faktor petak utama adalah teknik budidaya padi beras merah $(\mathrm{T} 1=$ konvensional; $\mathrm{T} 2=$ sistem aerobik tumpangsari dengan kacang tanah yang ditanam-sisip antar barisan padi), dan faktor anak petak adalah pola barisan padi beras merah (B1= barisan normal atau single row; B2= barisan kembar atau double row; B3= barisan triple row). Hasil penelitian menunjukkan bahwa teknik budidaya padi berpengaruh nyata terhadap pertumbuhan dan komponen hasil tanaman jagung ketan, yaitu lebih tinggi jika ditanam pasca padi sistem aerobik tumpangsari dengan kacang tanah dibandingkan dengan pasca padi kovensional. Pola barisan padi pada umumnya tidak berpengaruh terhadap komponen hasil tanaman jagung ketan, namun terdapat interaksi yang signifikan antara kedua faktor perlakuan penanaman padi beras merah terhadap panjang tongkol dan berat biji pipilan kering per tanaman jagung ketan pasca padi beras merah. Hasil biji jagung ketan tertinggi pada barisan double-row (183,2 g/tanaman) atau single-row (164,1 g/tanaman) jika ditugal langsung pasca padi sistem aerobik tumpangsari dengan kacang tanah, sedangkan jika pasca padi konvensional, hasil biji tertinggi pada pola barisan triple-row (58,4 g/tanaman).
\end{abstract}

Kata kunci: jagung ketan, padi beras merah, konvensional, sistem aerobik

\section{ABSTRACT}

In the paddy fields, farmers generally plant secondary food crops including maize in the dry season following lowland rice, when the availability of irrigation water is insufficient for growing rice crop. This study aimed to determine the effect of rice cultivation techniques between conventional and aerobic irrigation systems intercropped with peanuts on the growth and yield components of waxy maize of local Bima variety, which was direct-seeded following paddy rice without tillage. The experiment was carried out in a paddy-field located in Beleke Village, Gerung District, West Lombok, from September to December 2018, arranged according to the Split Plot Design with three blocks (replications) and two treatment factors. The main plot factor was red rice cultivation techniques (T1= conventional; $T 2=$ aerobic rice system intercropped with peanuts), and the subplot factor was the pattern of red rice rows $(B 1=$ normal or single row; $B 2=$ twin row or double row; $B 3=$ triple row). The results indicated that rice cultivation techniques significantly affected growth and yield components of the waxy maize, which was higher if planted following red rice with aerobic systems intercropped with peanuts compared with planting following conventional rice. The patterns of rice rows in general did not affect yield components of waxy maize, but there were significant interaction effects between the two treatment factors on cob length and the weight of dry grains per maize plant. The highest yields of waxy maize were on double (183.2 g/plant) or single row (164.1 g/plant) if the waxy maize was direct-seeded following aerobic rice intercropped with peanuts, whereas if direct-seeded following conventional rice, the highest grain yield of the waxy maize was on the triple-row pattern (58.4 g/plant).

Keywords: waxy maize, red rice, conventional technique, aerobic rice system 


\section{PENDAHULUAN}

Jagung (Zea mays L.) merupakan tanaman yang serbaguna, karena semua bagian tanaman di atas tanah dapat dimanfaatkan baik sebagai bahan pangan, pakan ternak maupun bahan baku industri (Purwono dan Purnamawati, 2007), dan bahkan limbahnya, seperti tongkol kering, dapat dipergunakan sebagai bahan bakar. Di Indonesia, jagung merupakan bahan makanan pokok kedua setelah beras, yang lebih banyak dikonsumsi dalam bentuk produk olahan atau bahan setengah jadi, seperti bahan campuran pembuatan kue, bubur instan, campuran kopi dan produk minuman rendah kalori. Konsumsi per kapita jagung dalam negeri untuk pangan mencapai $15 \mathrm{~kg}$ (Suprapto dan Marzuki, 2002).

Jagung ketan (Zea mays ceratina Kluesh) merupakan tanaman hortikultura yang cukup digemari oleh masyarakat, karena merupakan sumber karbohidrat utama setelah beras. Di samping itu, jagung ketan memiliki karakter spesial yaitu pati dalam bentuk 100\% amilopektin memiliki rasa manis, pulen dan penampilan menarik yang tidak dimiliki jagung lain (Mahendradatta dan Tawali, 2008). Jagung ketan dapat di manfaatkan untuk diversifikasi pangan, misalnya jagung pulut masak susu bisa diolah menjadi susu, puding dan es krim. Pati jagung dapat diolah menjadi bahan pengisi olahan, pengental makanan dan biskuit. Sementara tepung jagung dapat diolah menjadi olahan kue tradisional untuk subtitusi terigu seperti stik, cookies dan beras analog (Anonim, 2019).

Di Nusa Tenggara Barat, jagung telah menjadi tanaman pangan primadona yang banyak diusahakan petani di lahan kering pada musim hujan dan di lahan sawah pada musim kemarau, dengan adanya program PIJAR, namun hasil yang dicapai petani masih rendah. Luas panen jagung di NTB pada tahun 2006 seluas 40.617 ha dengan produktivitas 2,56 t/ha (BPS NTB, 2007). Angka ini masih rendah dibanding produktivitas nasional yang mencapai 3,47 t/ha. Hasil penelitian Balai Penelitian Serealia yang memadukan jagung varietas unggul bermutu baik dengan introduksi teknologi inovatif, telah dapat mencapai produktivitas sebesar $7-9 \mathrm{t} / \mathrm{ha}$ (Saenong dan Subandi, 2002), sementara hasil yang diperoleh petani dengan penerapan paket rekomendasi teknologi baru dapat mencapai hasil $5-6$ t/ha (Wahid, et al., 2002). Hasil kajian di lahan kering Sambelia Lombok Timur melalui perbaikan teknologi budidaya, jagung varietas Lamuru dapat mencapai hasil 7,87 t/ha, yaitu lebih tinggi dibanding teknologi petani 4,81 t/ha (Zubactirodin, et al., 2004).

Namun demikian, pada umumnya petani, terutama para petani di wilayah kabupaten Lombok Barat selalu menanam jagung di lahan sawah di musim kemarau pasca panen padi sawah. Menurut beberapa peneliti, tanah yang digunakan untuk budidaya padi sistem tergenang akan menyebabkan ketersediaan P bagi tanaman non-padi menjadi sangat rendah ketika dikeringkan untuk membudidayakan tanaman palawija (Sah dan Mikkelsen, 1986; Muirhead dan Humphreys, 1996). Selain itu, populasi fungi mikoriza arbuskular (FMA) di dalam tanah sangat menurun akibat tanah digunakan untuk budidaya tanaman padi secara tergenang (Ilag et al., 1987; Wangiyana et al., 2006; Wangiyana et al., 2016). Penelitian ini bertujuan untuk mengetahui pengaruh teknik budidaya padi antara teknik konvensional dan sistem irigasi aerobik padi tumpangsari dengan kacang tanah terhadap pertumbuhan dan hasil tanaman jagung ketan sistem tugal langsung pasca padi tanpa olah tanah.

\section{METODE PENELITIAN}

\section{Perlakuan dan rancangan percobaan}

Percobaan dilaksanakan di lahan sawah petani di Desa Beleke, Kecamatan Gerung, Lombok Barat, dari bulan September sampai Desember 2018, yang ditata menurut Rancangan Split Plot dengan dua faktor perlakuan. Faktor petak utama adalah teknik budidaya padi beras merah $(\mathrm{T} 1=$ padi konvensional (sistem tergenang); $\mathrm{T} 2=$ padi sistem irigasi aerobik pada bedeng tumpangsari dengan kacang tanah yang ditanam-sisip antar barisan padi), dan faktor anak petak adalah pola barisan padi beras merah $(\mathrm{B} 1=$ barisan normal atau single row; $\mathrm{B} 2=$ barisan kembar atau double row; $\mathrm{B} 3=$ barisan triple row). Dengan demikian diperoleh enam kombinasi perlakuan dan tiap kombinasi perlakuan dibuat dalam tiga blok (ulangan).

\section{Pelaksanaan percobaan}

\section{Penanaman}

Percobaan penanaman jagung ketan ini dilaksanakan pada bedeng dan petak percobaan bekas tanaman padi, untuk menguji dampak teknik budidaya padi terhadap jagung ketan yang ditugal langsung setelah panen padi tanpa olah tanah. Oleh karena itu, sebelum tanam jagung ketan, terlebih dahulu dilakukan pembersihan bedeng bekas padi sistem irigasi aerobik dan petak-petak bekas padi konvensional, dengan cara membersihkan gulma maupun sisa tanaman padi sebelumnya. Ukuran bedeng dan petak-petak perlakuan penanaman padi sebelumnya adalah $3 \times 1 \mathrm{~m}$ (luas $3 \mathrm{~m}^{2}$ ) sebanyak sembilan (9) petak bekas perlakuan padi konvensional dan sembilan (9) bedeng bekas penanaman padi sistem aerobik tumpangsari dengan kacang tanah. Selanjutnya, benih jagung ketan varietas lokal Bima yang telah disiapkan ditugal langsung pada 9 bedeng dan 9 petak perlakuan bekas penanaman padi ini. Sebelum ditanam, benih jagung ketan terlebih dahulu direndam dalam campuran (1:1) larutan Atonik $2 \mathrm{ml} /$ liter dan Cruiser $1 \mathrm{ml} /$ liter, dan perendaman dilakukan selama $12 \mathrm{jam}$. 
Selanjutnya, benih dicampur dengan Saromyl 35 SD untuk mencegah timbulnya penyakit bulai pada tanaman jagung ketan. Benih jagung ditanam dengan sistem tugal sedalam kurang lebih $3 \mathrm{~cm}$ dengan memasukkan satu (1) benih jagung ketan pada lubang tanam, yang juga diberi Furadan $3 \mathrm{G}$ dan selanjutnya ditutup dengan tanah. Jarak tanam antar barisan $75 \mathrm{~cm}$, dalam barisan $20 \mathrm{~cm}$ pada lahan pasca padi konvensional dan aerobik tumpangsari dengan kacang tanah.

\section{Pemupukan}

Pupuk yang digunakan adalah pupuk Phonska $300 \mathrm{~kg} / \mathrm{ha}$ atau setara dengan 4,5 g/tanaman dan pupuk Urea $100 \mathrm{~kg} / \mathrm{ha}$ atau setara dengan 1,5 g/tanaman, dengan cara ditugal $5 \mathrm{~cm}$ di samping pangkal batang jagung sedalam $5 \mathrm{~cm}$. Pemupukan dasar pada tanaman jagung, diberikan pada umur 10 hari setelah tanam (HST) dengan menggunakan pupuk Phonska, sedangkan, pemupukan susulan pada tanaman jagung, diberikan pada umur 46 hari setelah tanam (HST) dengan menggunakan pupuk urea.

\section{Pemeliharaan tanaman}

Penyulaman dilakukan pada saat tanaman berumur 7-9 HST dengan cara mengganti tanaman yang tidak tumbuh atau tanaman yang pertumbuhannya kurang baik dengan tanaman penyulam yang dipindahkan bersama dengan tanahnya. Pengendalian hama dan penyakit dilakukan dengan insektisida Virtako dan Regent secara bergantian yaitu pada umur 15, 30, 45 dan 60 HST untuk pengendalian berbagai jenis hama seperti ulat, belalang dan penggerek batang dan tongkol. Pengairan dilakukan menjelang tanam, dan pengairan selanjutnya dilakukan pada umur 30, 45, dan pada saat pengisian biji. Air yang diberikan bersumber dari sumur yang dialirkan dengan mesin pompa air melalui parit antar bedeng dan petak perlakuan.

\section{Variabel pengamatan dan analisis data}

Variabel yang diamati meliputi tinggi tanaman 56 HST (tinggi maksimum), jumlah daun 42 HST, jumlah daun hijau saat panen, lingkar batang saat panen, berat berangkasan kering per tanaman, panjang tongkol tanpa kelobot, lingkar tongkol tanpa kelobot, berat 100 biji kering pipil, berat biji kering pipil (hasil biji) per tanaman, dan indeks panen. Data dianalisis menggunakan Analisis Keragaman (Analysis of Variance (ANOVA)) dan uji Beda Nyata Jujur (Tukey's HSD) pada taraf nyata 5\%, menggunakan program CoStat for Windows ver. 6.303.

\section{HASIL DAN PEMBAHASAN}

Hasil Anova terhadap semua variabel pengamatan, yanng dirangkumkan dalam Tabel 1, meunjukkan bahwa teknik budidaya padi berpengaruh nyata terhadap hampir semua variabel pertumbuhan dan komponen hasil tanaman jagung ketan yang ditugal langsung pasca padi, kecuali terhadap jumlah daun hijau pada saat panen. Pola barisan padi juga berpengaruh nyata tetapi hanya terhadap jumlah daun 42 HST, berat berangkasan kering per tanaman, dan indeks panen. Juga terdapat pengaruh interaksi antara kedua faktor perlakuan tetapi hanya terhadap panjang tongkol, hasil biji kering pipil dan indeks panen.

Tabel 1. Rangkuman hasil ANOVA pengaruh teknik budidaya padi sistem aerobik tumpangsari dengan kacang tanah dan pola barisan padi beras merah terhadap pertumbuhan dan komponen hasil tanaman jagung ketan yang ditugal langsung pasca padi

\begin{tabular}{lccc}
\hline \multirow{2}{*}{ Variabel pengamatan jagung ketan } & \multicolumn{2}{c}{ Sumber Keragaman } \\
\cline { 2 - 5 } & Teknik budidaya padi & Pola barisan & Interaksi \\
\hline Tinggi tanaman 56 HST & $*$ & $\mathrm{~ns}$ & $\mathrm{~ns}$ \\
Jumlah daun 42 HST & $*$ & $*$ & $\mathrm{~ns}$ \\
Jumlah daun hijau saat panen & $\mathrm{ns}$ & $\mathrm{ns}$ & $\mathrm{ns}$ \\
Lingkar batang saat panen & $*$ & $\mathrm{~ns}$ & $\mathrm{~ns}$ \\
Berat berangkasan kering per tanaman & $* *$ & $* *$ & $\mathrm{~ns}$ \\
Panjang tongkol tanpa kelobot & $* *$ & $\mathrm{~ns}$ & $*$ \\
Lingkar tongkol tanpa kelobot & $*$ & $\mathrm{~ns}$ & $\mathrm{~ns}$ \\
Berat 100 biji kering pipil & $*$ & $\mathrm{~ns}$ & $\mathrm{~ns}$ \\
Berat biji kering pipil per tanaman & $* * *$ & $\mathrm{~ns}$ & $* *$ \\
Indeks panen & $*$ & $*$ & $* *$ \\
\hline
\end{tabular}

Keterangan: $\mathrm{ns}=$ non-signifikan; $* * *, * * *=$ signifikan pada $p$-value $=0,05 ; 0,01$ dan 0,001 , berturut-turut.

Berdasarkan pengaruh interaksi antar faktor perlakuan, dapat dilihat dari Gambar 1, Gambar 2 dan Gambar 3, bahwa nilai rata-rata umunya lebih tinggi pada jagung ketan yang ditanam pasca padi sistem aerobik tumpangsari dengan kacang tanah dibandingkan dengan pasca padi konvensional, kecuali rata-rata indeks panen, yang tertinggi pada jagung ketan yang ditanam pasca padi konvensional pola barisan triple. Jagung ketan 
yang ditanam pasca padi barisan triple-row, rata-rata lubang tugal tanaman berada di antara barisan triple-row padi beras merah yang berjarak $35 \mathrm{~cm}$ (Dulur et al., 2019). Karena barisan jagung ketan pasca padi pola triplerow jatuh pada posisi antar barisan yang paling lebar, maka diduga tanaman jagung ketan pasca pola barisan triple-row akan mendapat unsur hara yang relatif lebih banyak dibandingkan pasca pola barisan single atau double-row. Sebaliknya, pasca padi sistem aerobik tumpangsari dengan kacang tanah, maka di antara tiga pola barisan padi, populasi kacang tanah yang disisip antar barisan padi beras merah menjadi paling rendah pada pola triple-row dibandingkan dengan pola double atau single-row, karena pada pola single-row barisan kacang tanah disisip di antara tiap barisan padi beras merah (Dulur et al., 2019).

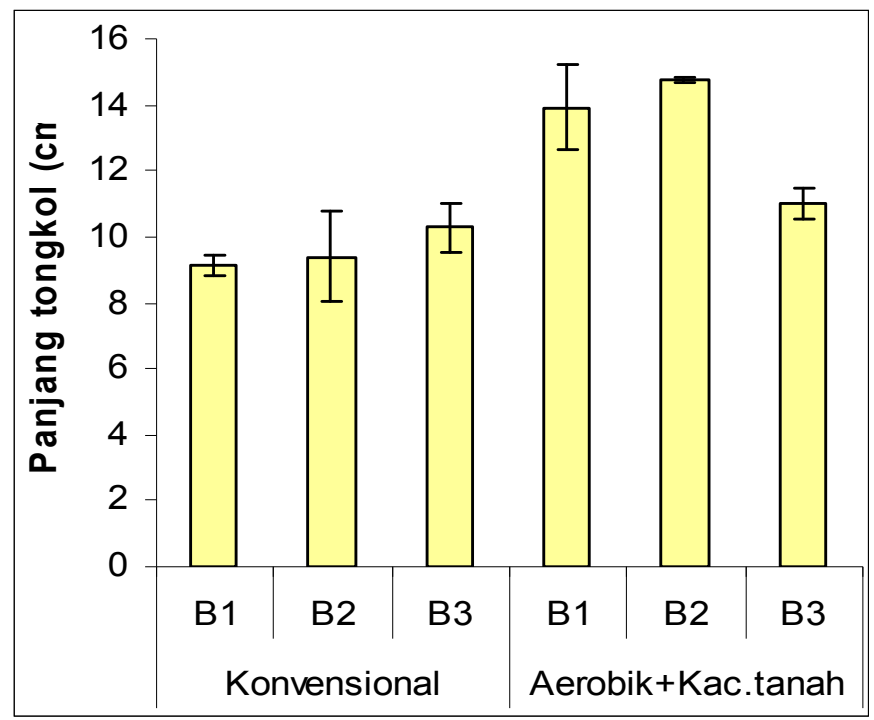

Gambar 1. Rerata (Mean $\pm \mathrm{SE}$ ) panjang tongkol $(\mathrm{cm})$ jagung pasca padi sebagai pengaruh interaksi antara teknik budidaya dan pola barisan padi

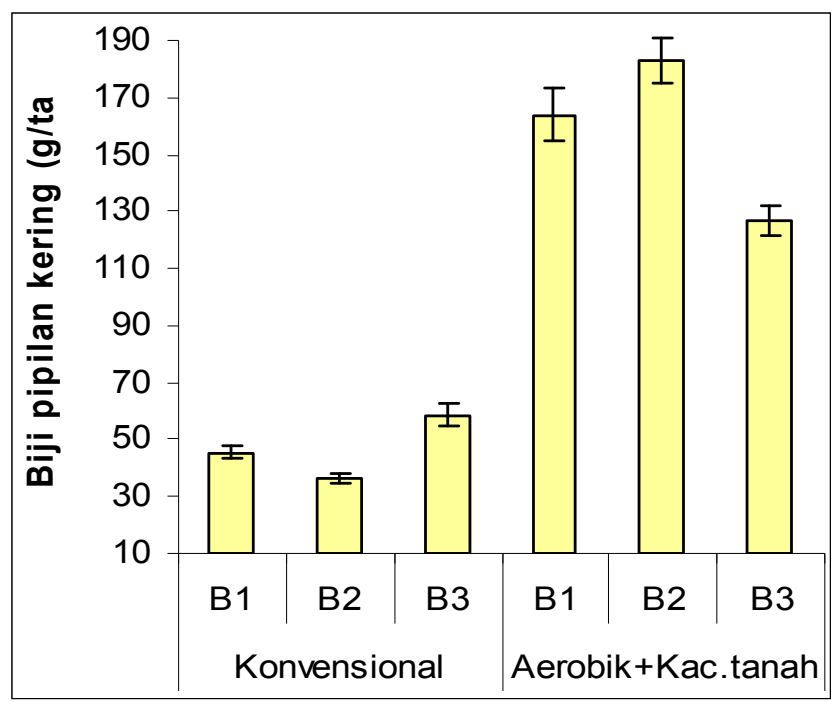

Gambar 2. Rerata (Mean \pm SE) hasil biji kering pipil (g/tanaman) jagung pasca padi sebagai pengaruh interaksi antara teknik budidaya dan pola barisan padi

Tanaman legume, termasuk kacang tanah, melalui simbiosisnya dengan bakteri bintil akar (Rhizobium sp.) dan fungi mikoriza arbuskular (FMA) akan dapat melakukan fiksasi $\mathrm{N}_{2}$ udara dan akan didepositkan ke dalam tanah (rizosfirnya), yang dikenal dengan istilah nitrogen rhizodeposition, yang dapat meningkatkan ketersediaan berbagai unsur hara di dalam tanah (Peoples et al., 1995; Inal at al., 2007; Fustec et al., 2010). Inilah yang diduga menyebabkan lebih tingginya hasil biji jagung ketan yang ditanam pasca padi beras merah sistem aerobik tumpangsari dengan kacang tanah dibandigkan dengan pasca padi sistem konvensional, seperti dapat dilihat dari Gambar 1 dan Gambar 2. Namun demikian, indeks panen jagung ketan relatif lebih tinggi pada penanaman pasca padi sistem konvensional dibandingkan dengan pasca padi sistem aerobik karena berat 
berangkasan kering jagung ketan pasca padi sistem konvensional jauh lebih rendah daripada pasca padi sistem aerobik tumpangsari dengan kacang tanah (Tabel 2)

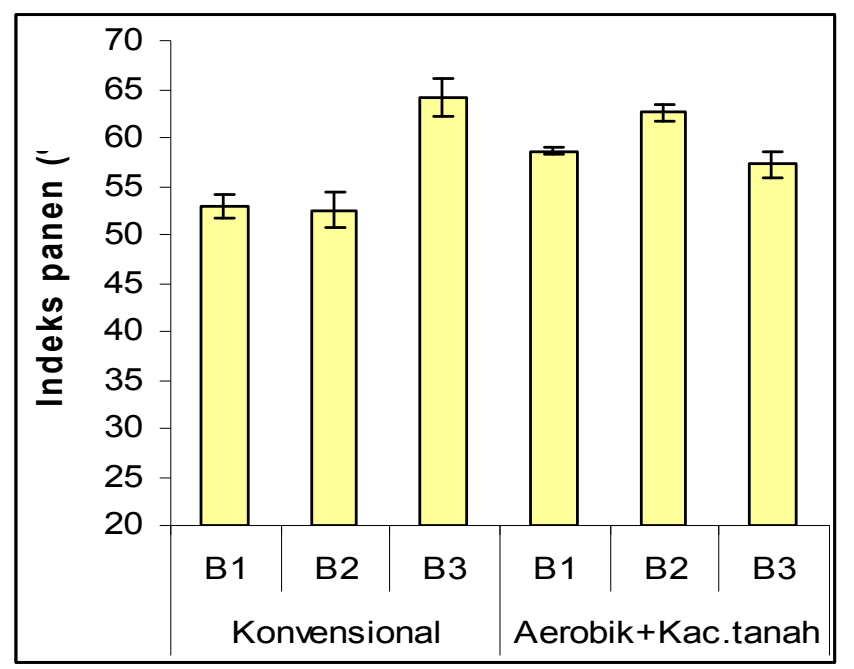

Gambar 3. Rerata (Mean \pm SE) indeks panen (\%) jagung pasca padi sebagai pengaruh interaksi antara teknik budidaya dan pola barisan padi

Tabel 2 juga menunjukkan bahwa selain berat berangkasan kering, ukuran tanaman lainnya, seperti tinggi tanaman, jumlah daun 42 HST dan lingkar batang tanaman jagung rata-rata lebih rendah jika ditanam pasca padi konvensional dibandingkan dengan pasca padi siste aerobik tumpangsari dengan kacang tanah. Variabel lainnya, seperti panjang tongol, lingkar tongkol, hasil biji kering pipil, berat 100 biji kering, dan indeks panen, juga signifikan lebih rendah pada jagung ketan yang ditanam pasca padi konvensional dibandingkan dengan pasca padi sistem aerobik tumpangsari dengan kacang tanah (Tabel 3).

Tabel 2. Rata-rata tinggi tanaman 56 HST, jumlah daun 42 HST, jumlah daun hijau saat panen, lingkar batang, dan berat berangkasan kering per tanaman jagung ketan pasca padi untuk setiap perlakuan pola barisan padi dan teknik budidaya padi

\begin{tabular}{lccccc}
\hline Perlakuan & $\begin{array}{l}\text { Tinggi tanaman } \\
\text { 56 HST }(\mathrm{cm})\end{array}$ & \multicolumn{2}{l}{$\begin{array}{l}\text { Jumlah daun 42 } \\
\text { HST }\end{array}$} & $\begin{array}{l}\text { Jumlah daun hijau Lingkar batang } \\
\text { saat panen }\end{array}$ & $\begin{array}{l}\text { Berat berang- } \\
\text { kasan kering } \\
(\mathrm{g} / \tan )\end{array}$ \\
\hline B1: Single & $171.05 \mathrm{a}$ & $9.52 \mathrm{ab}$ & $4.17 \mathrm{a}$ & $5.60 \mathrm{a}$ & $78.21 \mathrm{a}^{1)}$ \\
B2: Double & $172.92 \mathrm{a}$ & $9.03 \mathrm{~b}$ & $3.92 \mathrm{a}$ & $5.35 \mathrm{a}$ & $71.29 \mathrm{ab}$ \\
B3: Triple & $178.07 \mathrm{a}$ & $9.73 \mathrm{a}$ & $3.25 \mathrm{a}$ & $5.52 \mathrm{a}$ & $63.53 \mathrm{~b}$ \\
BNJ 0.05 & 21.05 & 0.63 & 2.35 & 0.57 & 9.36 \\
\hline T1: Konvensional & $132.68 \mathrm{~b}$ & $7.72 \mathrm{~b}$ & $3.22 \mathrm{a}$ & $4.75 \mathrm{~b}$ & $35.28 \mathrm{~b}$ \\
T2: Aerobik + KT & $215.34 \mathrm{a}$ & $11.13 \mathrm{a}$ & $4.33 \mathrm{a}$ & $6.23 \mathrm{a}$ & $106.74 \mathrm{a}$ \\
BNJ 0.05 & 41.99 & 1.69 & 3.57 & 1.07 & 18.03 \\
\hline
\end{tabular}

1) Nilai rerata pada setiap kolom yang diikuti huruf yang sama, tidak berbeda nyata antar aras dari tiap faktor perlakuan

Hal ini semua mengindikasikan bahwa jagung ketan yang ditanam tugal langsung pasca padi konvensional lebih menderita kekurangan unsur hara, terutama $\mathrm{N}$ dan $\mathrm{P}$, jika dibandingkan dengan yang ditanam pasca padi sistem aerobik tumpangsari dengan kacang tanah. Selain karena ada peningkatan ketersediaan unsur hara pasca penanaman kacang tanah pada sistem padi aerobik tumpangsari dengan kacang tanah, tanaman padi sistem irigasi konvensional, yaitu sistem tergenang, dilaporkan menyebabkan banyak kehilangan unsur hara nitrogen dalam suasana tergenang, terutama melalui volatilisasi akibat suasana tanah yang anaerobik (Buresh et al., 1991; De Datta et al., 1991), selain juga ada kehilangan hara melalui leaching $\mathrm{N}$ dan P (Peng et al., 2011). Selain itu, pengeringan tanah sawah sistem tergenang juga dilaporkan menurunkan ketersediaan P bagi tanaman palawija yang ditanam pasca padi sistem tergenang (Sah dan Mikkelsen, 1986; Muirhead dan Humphreys, 1996). Oleh karena itu, dalam kondisi penanaman palawija seperti ini dibutuhkan adanya simbiosis antara tanaman palawija dan FMA, dan tanaman jagung merupakan tanaman yang mempunyai ketergantungan yang tinggi (73\%) terhadap simbiosis dengan FMA (Tawaraya, 2003). Padahal, teknik budidaya padi sistem tergenang sangat signifikan menurunkan populasi FMA di dalam tanah (Ilag et al., 1987; 
Wangiyana et al., 2006; Wangiyana et al., 2016). Oleh karena itu, teknik budidaya padi sistem tergenang sangat merugikan tanaman palawija yang ditanam pasca padi.

Tabel 3. Rata-rata panjang tongkol, lingkar tongkol, berat biji kering pipil, berat 100 biji, dan indeks panen jagung ketan pasca padi untuk setiap perlakuan pola barisan padi dan teknik budidaya padi

\begin{tabular}{lccccc}
\hline Perlakuan & $\begin{array}{l}\text { Panjang tongkol } \\
(\mathrm{cm})\end{array}$ & \multicolumn{2}{l}{$\begin{array}{l}\text { Lingkar tongkol Berat biji pipilan } \\
(\mathrm{cm})\end{array}$} & $\begin{array}{c}\text { kering }(\mathrm{g} / \mathrm{tan}) \\
\text { Berat } 100 \mathrm{biji}(\mathrm{g})\end{array}$ & $\begin{array}{l}\text { Indeks panen } \\
(\%)\end{array}$ \\
\hline B1: Single & $11.53 \mathrm{a}$ & $13.03 \mathrm{a}$ & $104.79 \mathrm{a}$ & $17.91 \mathrm{a}$ & $55.76 \mathrm{~b}^{1)}$ \\
B2: Double & $12.08 \mathrm{a}$ & $12.73 \mathrm{a}$ & $109.83 \mathrm{a}$ & $20.77 \mathrm{a}$ & $57.56 \mathrm{ab}$ \\
B3: Triple & $10.64 \mathrm{a}$ & $12.87 \mathrm{a}$ & $92.59 \mathrm{a}$ & $21.24 \mathrm{a}$ & $60.69 \mathrm{a}$ \\
BNJ 0.05 & 2.30 & 1.15 & 19.39 & 4.81 & 4.23 \\
\hline T1: Konvensional & $9.60 \mathrm{~b}$ & $11.69 \mathrm{~b}$ & $46.80 \mathrm{~b}$ & $16.60 \mathrm{~b}$ & $56.53 \mathrm{~b}$ \\
T2: Aerobik + KT & $13.23 \mathrm{a}$ & $14.06 \mathrm{a}$ & $158.01 \mathrm{a}$ & $23.34 \mathrm{a}$ & $59.47 \mathrm{a}$ \\
BNJ 0.05 & 0.92 & 1.23 & 9.66 & 4.92 & 2.73 \\
\hline
\end{tabular}

1) Nilai rerata pada setiap kolom yang diikuti huruf yang sama, tidak berbeda nyata antar aras dari tiap faktor perlakuan

\section{KESIMPULAN DAN SARAN}

Dapat disimpulkan bahwa teknik budidaya padi sangat berpengaruh terhadap pertumbuhan dan hasil tanaman jagung ketan yang ditanam pasca padi dengan sistem tabela (tanam benih langsung) tanpa olah tanah, di mana teknik budidaya padi sistem tergenang sangat merugikan tanaman jagnng ketan pasca padi, jika dibandingkan dengan teknik budidaya pasi sistem aerobik pada bedeng permanent, tumpangsari dengan kacang tanah.

\section{UCAPAN TERIMA KASIH}

Melalui artikel ini penulis menyampaikan terima kasih kepada Direktorat Riset dan Pengembangan, Kementerian Riset, Teknologi, dan Pendidikan Tinggi, serta Rektor Universitas Mataram, dan Ketua Lembaga Penelitian Universitas Mataram, atas dana penelitian PDUPT yang telah diberikan.

\section{DAFTAR PUSTAKA}

Anonim. 2019. Jagung Pulut untuk Diversifikasi Pangan. http//balitsereal.litbang.pertanian.go.id/jagung-pulutuntuk-diversifikasi-pangan. Diakses, 28 Mei 2019.

BPS NTB, 2007. Nusa Tenggara Barat dalam Angka. Badan Pusat Statistik Propinsi NTB. Mataram.

Buresh, R.J., De Datta, S.K., Samson, M.I., Phongpan, S., Snitwongse, P., Fagi, A.M. and Tejasarwana, R. 1991. Dinitrogen and Nitrous Oxide Flux from Urea Basally Applied to Puddled Rice Soils. Soil Sci. Soc. Am. J., 55: 268-273.

De Datta, S.K., Buresh, R.J., Samson, M.I., Obcemea, W.N. and Real, J.G. 1991. Direct Measurement of Ammonia and Denitrification Fluxes from Urea Applied to Rice. Soil Sci. Soc. Am. J., 55: 543-548.

Dulur, N.W.D., Wangiyana, W., Farida, N., and Kusnarta, I.G.M. 2019. Improved Growth and Yield Formation of Red Rice under Aerobic Irrigation System and Intercropping with Peanuts. IOSR Journal of Agriculture and Veterinary Science (IOSR-JAVS), Vol. 12, Issue 8, Ser. I: 12-17.

Fustec, J., F. Lesuffleur, S. Mahieu, J.-B. Cliquet, 2010. Nitrogen rhizodeposition of legumes. A review. Agron. Sustain. Dev., 30: 57-66.

Ilag, L.L., A.M. Rosales, F.A. Elazegui and T.W. Mew, 1987. Changes in the population of infective endomycorrhizal fungi in a rice-based cropping system. Plant and Soil, 103:67-73.

Inal, A., Gunes, A., Zhang, F., and Cakmak, I. 2007. Peanut/maize intercropping induced changes in rhizosphere and nutrient concentrations in shoots. Plant Physiology and Biochemistry, 45: 350-356.

Mahendradatta dan Tawali, 2008. Jagung dan Diversifikasi Produk Olahannya. Masagena Press. Makasar.

Muirhead, W.A. and E. Humphreys, 1996. Rice-based cropping systems in Australia: Constraints to non-rice crops. p.181-185. In: G. Kirchhof and H.B. So (Eds), Management of Clay Soils for Rainfed Lowland Rice-based Cropping Systems. Canberra, Australia: ACIAR.

Peng, S.Z., Yang, S.H., Xu, J.Z., Luo, Y.F., Hou, H.J. 2011. Nitrogen and phosphorus leaching losses from paddy fields with different water and nitrogen managements. Paddy and Water Environ., 9:333-342. 
Peoples, M.B., Herridge, D.E., and Ladha, J.K. 1995. Biological nitrogen fixation: An efficient source of nitrogen for sustainable agricultural production? Plant and Soil, 174: 3-28.

Purwono dan H. Purnamawati, 2007. Budidaya 8 Jenis Tanaman Pangan Unggul. Penebar Swadaya, Jakarta.

Saenong, S. dan Subandi, 2002. Konsep PTT pada Tanaman Jagung. Makalah disampaikan pada Pembinaan Teknis dan Manajemen PTT Palawija di Balitkabi. Malang 21 - 22 Desember 2002.

Sah, R.N. and D.S. Mikkelsen, 1986. Sorption and bioavailability of phosphorus during the drainage period of flooded-drained soils. Plant and Soil, 92: 265-278.

Suprapto, H.S., dan H.A.R. Marzuki, 2002. Bertanam Jagung. Penebar Swadaya. Jakarta.

Tawaraya, K., 2003. Arbuscular mycorrhizal dependency of different plant species and cultivars. Soil Science and Plant Nutrition, 49(5): 655-668.

Wahid, A.S., Zainuddin, dan S. Saenong, 2002. Analisis Usahatani Pemupukan NPK Pelangi pada Tanaman Jagung di Kabupaten Gowa. Sulawesi Selatan pada MK. I. 2002. Studi Kasus Desa Pa'bundukang, Kabupaten Gowa. Sulsel. Kerja sama BPTP Sulsel dengan PT. Panen Mas Agromandiri dan PT. Pupuk Kaltim.

Wangiyana, W, P.S. Cornish, and E.C. Morris, 2006. Arbuscular Mycorrhizal Fungi Dynamics in Contrasting Cropping Systems on Vertisol and Regosol Soils of Lombok, Indonesia. Experimental Agriculture (Cambridge), 42: 427-439.

Wangiyana, W., P.S. Cornish, and M.H. Ryan, 2016. Arbuscular Mycorrhizas in Various Rice Growing Environments and their Implication for Low Soybean Yields on Vertisol Soil in Central Lombok, Indonesia. IOSR Journal of Environmental Science, Toxicology and Food Technology, 10(12 Ver. III): 51-57.

Zubactirodin, S. Saenong, Subandi, dan A. Hipi. 2004. Budidaya Jagung Pada Lahan Kering Melalui Pendekatan Pengelolaan dan Sumberdaya dan Tanaman Terpadu (PTT) hal.111 - 130, Dalam Prosiding Seminar Nasional "Pemberdayaan Petani Miskin di Lahan Marginal Melalui Inovasi Teknologi Tepat Guna. Mataram 31 Agustus - 1 September 2004. 